Document downloaded from:

http://hdl.handle.net/10251/67633

This paper must be cited as:

Peinado Pardo, I.; Rosa Barbosa, EM.; Heredia Gutiérrez, AB.; Escriche Roberto, MI.; Andrés Grau, AM. (2013). Influence of processing on the volatile profile of strawberry spreads made with isomaltulose. Food Chemistry. 138(1):621-629. doi:10.1016/j.foodchem.2012.09.104.

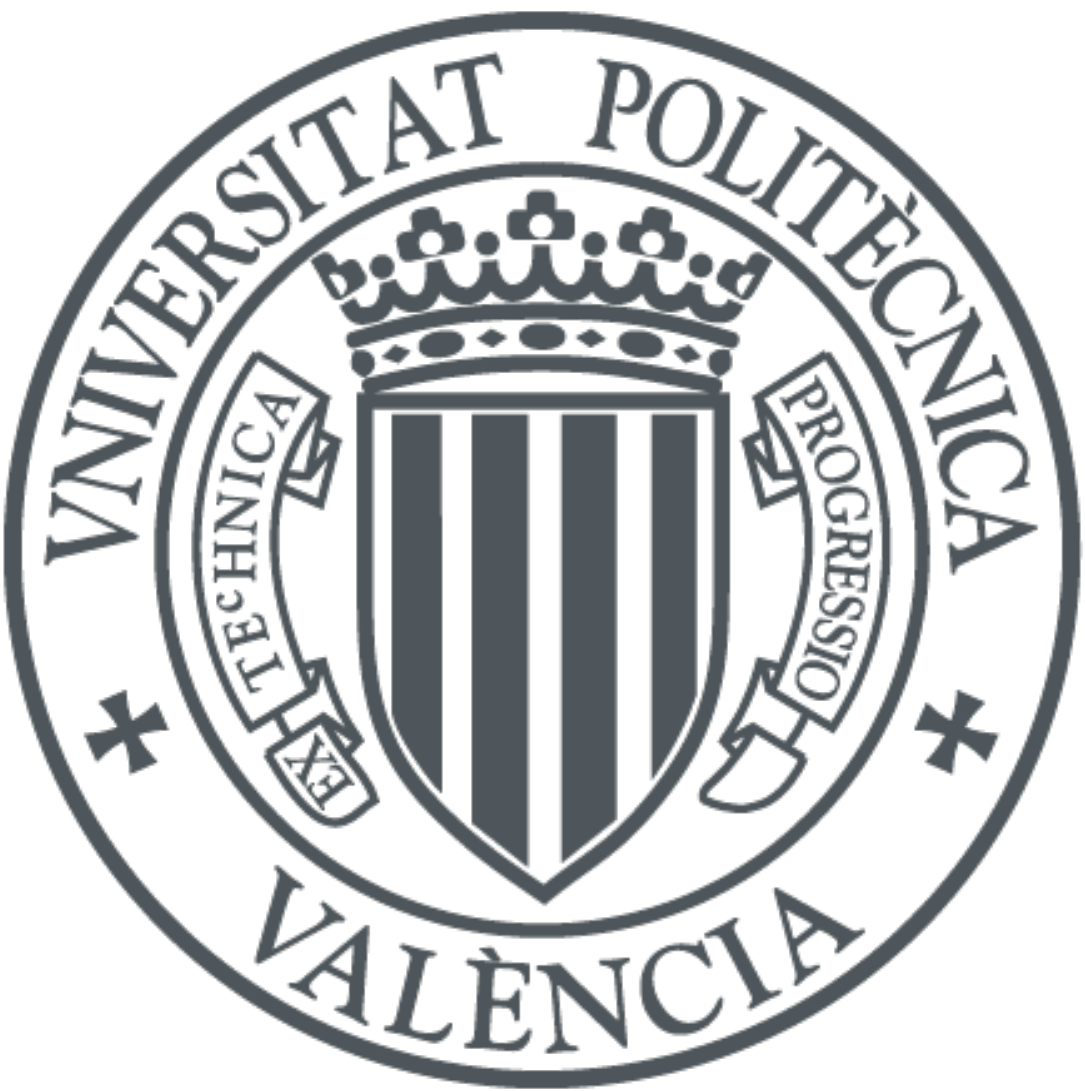

The final publication is available at

https://dx.doi.org/10.1016/j.foodchem.2012.09.104

Copyright Elsevier

Additional Information 


\title{
Influence of processing on the volatile profile of strawberry spreads made with isomaltulose
}

\author{
Peinado, I.; Rosa, E.; Heredia, A.; Escriche, I.* \& Andrés, A. \\ Institute of Food Engineering for Development, Universitat Politècnica de València, \\ P.O. Box 46022 Valencia, Spain \\ * Corresponding author. Tel.: +34 963877366; fax: +34 963877369 \\ E-mail address: iescrich@tal.upv.es
}

\section{Abstract}

A new strawberry spread formulated with fructose and isomaltulose (replacing sucrose partially or totally) and a high percentage of fruit was developed in line with the new trend of healthier products. This work analyses the influence of some process variables (percentage of sugar, pectin and citric acid, and time of thermal treatment) on the volatile profile of these spreads with different formulations. The ripeness of the raw strawberries influences the concentrations of some of the compounds in the spreads, such as isobutyl acetate, butyl butyrate, 3-hexen-1-yl acetate or propan-2-ol. The process conditions have an important effect on the volatile profiles. Most of the esters and alcohols suffer a decrease whereas 13 new compounds appear, mostly furans (furfural, 2-acetylfurane, 5-methyl furfural, mesifurane) and aldehydes (octanal, nonanal, decanal and benzaldeyhde). In general, the spreads formulated with sucroseisomaltulose, containing higher levels of pectin and citric acid gave better results in the preservation of the original aromatic compounds in raw strawberries.

Keywords: strawberry, healthy fruit spread, isomaltulose, volatile profile, aroma 


\section{Introduction}

Recently, the population of developed countries has modified its nutritional habits as a consequence of new life styles. In fact, many studies have reported that the new eating habits related to this life style are causing health problems. An example is the relationship established between fast food with obesity and diabetes 2 (Pereira, Kartashov, Ebbeling, Van Horn, Slattery, Jacobs \& Ludwig, 2005; Jeffery, Baxter, Mcguire \& Linde, 2006; Frank \& Vasanti, 2010; Fraser \& Edwards, 2010; McPhail, Chapmanb \& Beagan, 2011). From this point of view, the development of new products such as fruit spreads formulated with healthier sugars like fructose and isomaltulose would be interesting for certain groups of the population such as children and senior citizens. These products should not have undesirable effects like caries and diabetes (related with sugar consumption), and therefore would be more appropriate for these niches of the population than traditional jams.

Fruit is a food group which is receiving more attention among the population due to its interesting and healthy properties such as high functional and nutritional value, being rich in fibre, minerals, vitamins, terpens antioxidant compounds, etc.(Gillman, Cupples, Gagnon, Posner, Ellison, Castelli \& Wolf, 1995; Cavanah, Hipwell \& Wilkinson, 2003; Dhiraj, Vattem \& Shetty, 2005). Among the wide variety of available fruit, one of the most valued is the strawberry, not only because of its high content in vitamins and minerals, but also because of its organoleptic characteristics such as taste and aroma. Strawberries are rich in vitamin $\mathrm{C}$, sometimes in an even higher concentration than oranges. They are also rich in minerals (iron, iodine, calcium, phosphorus, magnesium and potassium (Ávila, Beltrán, Cuadrado, Del Pozo, Rodríguez \& Ruiz, 2009) and more than 33 identified organic acids, for example: citric, malic, oxalic, and folic, (Rizzolo, Lombardi, Lovati, Tagliabue \& Testoni 1995; Forney, Kalt, McDonald, \& Jordan, 1996; 
52 Azodanlau, Darbellay, Luisier, Villettaz, \& Amado, 2003, 2004). Strawberries are very

53 problematic for industrial processing as they are seasonal, and have a high water content

54 which makes them very perishable. Besides, strawberry has healthy, sensory characteristics which make it a very attractive fruit for processing. Therefore, the food industry has an increased interest in developing new kinds of processed fruit products whose sensorial characteristics are not very different to the fresh fruit. This could be the case of strawberry spreads, as they present some characteristics similar to fresh fruit but on the other hand are more stable than the fresh product since the $\mathrm{a}_{\mathrm{w}}$ and the moisture of the product are reduced. The big difference between a fruit spread and a jam is that in a fruit spread cooking to reach a final soluble solid content is avoided, as it provokes the greatest changes from a nutritional, sensorial and functional point of view. Moreover, a jam must have at least $45^{\circ}$ Brix, whereas a spread fruit does not have any restriction related to sugar content (BOE 04/07/07; RD: 863/2003). Additionally, these spreadable products might be considered healthier when the sucrose is replaced by other sweeteners such as isomaltulose, a sugar especially indicated for children and senior citizens as it does not produce caries, and moreover is slowly released in the blood (Matsuyama, Sato \& Hoshino, 1997; Schiweck, Munir, Rapp, Schenider, \& Bogel, 2000; Lina, Jonker \& Kozianowski, 2002).

The food industry is more and more concerned with the elaboration of healthier food products without forgetting the importance of taste and flavour, since they are very important characteristics from the consumers' point of view. These attributes which can be quantified in terms of the volatile profile are important for both the fresh and the processed product. In the case of strawberries, more than 360 volatile compounds have been identified, including esters and acids, together with alcohols, ketones, lactones and aldehydes in minor quantities (Larsen, Poll \& Olsen, 1992; Forney, 2001). Esters, which 
are responsible for the fruity, floral aroma make up more than $25 \%$ of the total mass of the volatiles in this ripe fruit (Maarse, 1991; Gomes da Silva \& Chaves das Neves, 1999; Forney, 2001). Aldehydes and furanones also play important roles in strawberry aroma (Forney, 2001; Bood \& Zabetakis, 2002), as well as Terpenic and sulfuric compounds, which have an important impact on the characteristic aroma of red berries even though they only represent a small portion of the volatile compounds (Dirinck, De Pooter, Willaert \& Schamp 1981; Azodanlau, et al., 2003, 2004).

The aim of this work was to analyze the influence of the different process variables (wt $\%$ of isomaltulose, wt $\%$ of pectin, wt $\%$ of citric acid and time of heat treatment) on the volatile profile of different strawberry fruit spreads made using healthier sugars such as isomaltulose or fructose to replace sucrose partially or totally.

\section{Material and Methods}

\subsection{Raw material}

Fifteen batches of raw strawberries (Fragaria vesca, Camarosa) acquired in a local supermarket, where used for the present work. The experimental work was performed between February and June of 2010. Each batch of strawberries was sorted in order to eliminate damaged fruit and group the samples in terms of colour, shape and ripeness. Then they were cut and washed in chlorinated water to eliminate possible field residues.

\subsection{Methodology}

Formulation of the spreadable products:

Following the surface-response methodology, a statistical central composite design $2^{4}+$ start (Gómez \& Gómez, 1984; Kaur, Wani, Oberoi \& Sogi., 2008) was applied to analyze the influence of four independent variables $X_{1}$ ( $\%$ of isomaltulose), $X_{2}$ ( $\%$ of pectin), $X_{3}$ (\% of citric acid) and $X_{4}$ (time of heat treatment) on the volatile profile of 
102 spreadable strawberry products (table 1). Two kinds of strawberry spread were

103 formulated following two identical replicates of the design. One group of samples

104 containing sucrose and isomaltulose (as sucrose was considered to be the reference

105 sugar) and a second group formulated with fructose and isomaltulose (both considered

106 healthy sugars). The target concentration of the final product was $50{ }^{\circ} \mathrm{Brix}$, therefore the

107 sweetness of the sugars was not a determinant parameter when the different mixtures

108 where made to formulate the products. These mixtures between two sugars were needed

109 since the solubility of isomaltulose does not permit the required final sugar

110 concentration of $50^{\circ}$ Brix (Kaga \& Mizutani, 1985; Schiweck et al., 2000).

111 The formulation of the products was the result of the implementation of dry osmotic

112 dehydration studied previously (Peinado, Rosa, Heredia \& Andrés, 2008, Rosa,

113 Peinado, Heredia \& Andrés, 2008). In this case, the product was directly formulated by

114 mixing the ingredients in the correct proportions to reach the established concentration

115 of 50 oBrix, therefore, avoiding the typical equilibrium stage which takes place during

116 osmotic dehydration. The amounts of raw strawberry and sugar needed were calculated

117 according to the correspondent mass balance and they were dependent on the soluble

118 solids content in the raw strawberries. The ingredients in the spreadable strawberry

119 products were: strawberries, sugars (sucrose or fructose, and isomaltulose), pectin (as a

120 gelling agent), potassium sorbate at a fixed concentration of $500 \mathrm{ppm}$ (as a

121 microbiological preserver) (Karabulut, Lurie \& Droby, 2001; Castelló, Fito \& Chiralt,

122 2006) and citric acid (as a colour preserver). Once the ingredients were mixed, the

123 product was heated until it reached $85^{\circ} \mathrm{C}$. This temperature was necessary to make "hot

124 canning" effective, as well as to allow the pectin to dissolve and then gel, so that the gel

125 structure would not break up during storage. Then, the product was placed in glass jars

126 and some of the samples, depending on the statistical design, were heated for $5,10,15$ 
127 or 20 minutes in a bath of boiling water. Finally, they were stored at room temperature

128 for 24 hours before the correspondent analyses were performed.

\subsection{Physicochemical analyses}

130 All the physicochemical analyses were carried out on raw strawberry puree, and the

131 final spreads. All measurements were carried out in triplicate.

132 Moisture content was determined gravimetrically by drying to a constant weight in a

133 vacuum oven at $60{ }^{\circ} \mathrm{C}\left(\operatorname{method} 20.103\right.$ AOAC, 1980). Soluble solids content $\left({ }^{\circ}\right.$ Brix)

134 was measured with a refractometer at $20^{\circ} \mathrm{C}$ (ATAGO $3 \mathrm{~T}$ ). For the strawberry spread,

135 dilution at a ratio of $4 \mathrm{~g}$ water for each gram of sample was necessary. Water activity

$136\left(\mathrm{a}_{\mathrm{w}}\right)$ was determined with a dew point hygrometer (FA-st lab, GBX) and pH was

137 determined with a pH-meter (SevenEasy, Mettler Toledo).

\section{$138 \quad$ 2.4. Volatile compound analysis}

139 Aromatic compounds were extracted by purge and trap thermal desorption; (Torres,

140 Chiralt \& Escriche, 2012) 20 g of raw strawberry or strawberry spread spiked with 200

$141 \mu \mathrm{L}$ 2-pentanol $(10 \mu \mathrm{g} / \mathrm{mL}$ as an internal standard $)$, were placed in a purging vessel flask

142 and left in a water bath at $45{ }^{\circ} \mathrm{C}$ for $20 \mathrm{~min}$. During this time, purified nitrogen $(150 \mathrm{~mL}$

$143 \mathrm{~min}^{-1}$ ) was forced through a porous filter placed at the bottom of the vessel, producing a

144 stream of bubbles which passed through the sample drawing the volatile compounds.

145 These were trapped in a $100 \mathrm{mg}$ porous polymer (Tenax TA, 20-35 mesh) packed into a

146 glass tube placed at the end of the system. A total of 3 extracts were obtained for each

147 sample. The volatile compounds were subsequently thermally desorbed using a direct

148 thermal desorber (TurboMatrix TD, Perkin ElmerTM, CT-USA). Desorption was

149 performed under a $10 \mathrm{~mL} \mathrm{~min}{ }^{-1}$ helium flow at $240{ }^{\circ} \mathrm{C}$ for $10 \mathrm{~min}$. The volatiles were

150 then cryofocused in a cold trap at $-30^{\circ} \mathrm{C}$ and transferred directly onto the head of the

151 capillary column by heating the cold trap to $250{ }^{\circ} \mathrm{C}$ (at a rate of $99{ }^{\circ} \mathrm{C} / \mathrm{s}$ ). 
152 GC-MS analyses were performed using a Finnigan TRACETM MS (TermoQuest,

153 Austin, USA). Volatile compounds were separated using a BP-20 capillary column

154 (SGE, Australia) (60 m length, $0.32 \mathrm{~mm}$ i.d., $1.0 \mathrm{~lm}$ film thickness). Helium at a

155 constant flow rate of $1 \mathrm{~mL} \mathrm{~min}^{-1}$ was used as a carrier gas. The temperature was

156 programmed to increase from $40{ }^{\circ} \mathrm{C}$ (2 min hold time) to $190{ }^{\circ} \mathrm{C}$ at $4{ }^{\circ} \mathrm{C} \mathrm{min}{ }^{-1}$ and

157 finally to $230{ }^{\circ} \mathrm{C}$ at $10^{\circ} \mathrm{C} \mathrm{min}^{-1}$. The MS interface and source temperatures were $250{ }^{\circ} \mathrm{C}$

158 and $200{ }^{\circ} \mathrm{C}$, respectively. Electron impact mass spectra were recorded in impact

159 ionization mode at $70 \mathrm{eV}$ and with a mass range of $\mathrm{m} / \mathrm{z} 33-433$. A total of three extracts

160 were obtained for each sample.

161 The volatile compounds were tentatively identified by comparing their mass spectra

162 ( $\mathrm{m} / \mathrm{z}$ values of the most important ions) with spectral data from the National Institute of

163 Standards and Technology 2002 library as well as retention indices published in the

164 literature (Kondjoyan \& Berdagué, 1996; pherobase.com). Relative retention indices

165 were determined by injection into the Tenax of a solution containing the homogenous

166 series of normal alkanes $\left(\mathrm{C}_{8}-\mathrm{C}_{20}\right.$; by Fluka Buchs, Schwiez, Switzerland $)$ in the same

167 temperature-programmed run, as described above. Semiquantitative analyses were

168 carried out (Soria, Martínez-Castro \& Sanz, 2008). Quantification was not considered

169 necessary since the objective of this study was to evaluate the differences between the

170 different treatments considering all of the identified compounds without being limited to

171 those for which standards were available.

172 The data $(\mu \mathrm{g} / 100 \mathrm{~g}$ of fresh strawberry) were expressed using the amount of internal

173 standard and the relative area of each compound with respect to that of the internal

174 standard, assuming a response factor equal to one.

175 2.5. Statistical analysis 
176 As it has already been mentioned, a central composite design was applied to analyze the

177 influence of four independent variables $X_{1}$ (\% of isomaltulose), $X_{2}$ (\% of pectin), $X_{3}$ (\%

178 of citric acid) and $X_{4}$ (time of thermal treatment) at five levels, on the aromatic profile

179 of the strawberry spreads.

180 The statistical analyses of variance (ANOVA) with a confidence level of $95 \%$ (p-value $181 \leq 0.05)$ were carried out by means of the software package Statgraphics Plus 5.1 to

182 estimate the significant differences between the raw strawberry batches used.

183 Furthermore, Principal Component Analysis, PCA, (Martens \& Næs, 1989)

184 (Unscrambler version 10.X; CAMO Process AS, Oslo, Norway) was applied to describe 185 the relationships between the volatile compounds and process variables (wt \% of 186 isomaltulose, wt $\%$ of pectin, wt $\%$ of citric acid ant time of heat treatment).

3. Results and discussion

3.1. Influence of formulation on the physicochemical parameters of spreadable strawberry products

191 In order to evaluate the natural variability of physicochemical parameters in the raw

192 batches due to their different levels of ripening, several analyses of variance (ANOVA) were performed. Table 2 shows the mean values and the standard deviation of the physicochemical parameters (water activity $\left(\mathrm{a}_{\mathrm{w}}\right)$, moisture content $\left(\mathrm{x}^{\mathrm{w}}\right)$, soluble solids content $\left(\mathrm{x}^{\mathrm{ss}}\right)$, and $\left.\mathrm{pH}\right)$ as well as the $\mathrm{F}$ - ratio obtained from the simple ANOVAs

196 performed. The results showed significant differences between the different raw

197 batches, which should be taken into account when formulating the product.

198 After processing, all the strawberry spreads showed a very similar composition in terms

199 of soluble solids $\left(\mathrm{x}^{\mathrm{ss}}\right)$ and moisture $\left(\mathrm{x}^{\mathrm{w}}\right)$ content as they were formulated in order to 200 reach a final concentration of $50^{\circ}$ Brix. Table 2 shows the water activity $\left(\mathrm{a}_{\mathrm{w}}\right)$ and $\mathrm{pH}$ 
201 values of the strawberry spreads for all the combinations of the different variables to

202 obtain 26 spreads with sucrose-isomaltulose and 26 products with fructose-

203 isomaltulose. The $\mathrm{pH}$ varied for the spreads, their values ranging between $3.03 \pm 0.42$,

204 for the spreads which had the lowest percentage of citric acid, and $2.80 \pm 0.03$ for the

205 spreads with the highest percentage of citric acid. These differences could have a direct

206 influence on the stability and acceptation of the product.

207 3.2. Influence of raw material and processing on the volatile profile of spreadable 208 strawberry products

20929 volatile compounds were tentatively identified and semi-quantified in the volatile 210 profile of raw strawberries. Table 3 shows the relative retention index (RI) calculated

211 for each volatile compound, their concentration in the different raw batches expressed 212 as $\mathrm{C}_{\mathrm{F}}$ ( $\mu \mathrm{g}$ of volatile compound / $100 \mathrm{~g}$ raw strawberry), as well as the statistical results

213 of the simple analysis of variance performed for each compound. These compounds 214 belong to four different chemical families: 16 esters, 10 alcohols, 2 aldehydes and 1

215 ketone. Specifically, ethyl hexanoate and methyl hexanoate (fresh fruity fragrance), 216 methyl octanoate (orange wine aroma) and ethyl octanoate (aquavit aroma) are some of 217 the main contributors to the strawberry volatile profile, which is consistent with 218 previous studies (Perez et al. 1992, 1997; Zhang et al., 2009). Some aldehydes, such as 219 hexenal, are also responsible for the typical green notes in this fruit. It is well know that 220 amino acids, sugars and lipids are precursors of aroma compounds of esters. In this 221 pathway, the bioconversion of the amino acids, sugars and lipids into acids, aldehydes or alcohols, and consequently into esters are catalyzed by two key enzymes: alcohol acyltransferases and alcohol dehydrogenases (Charles, 2000; Zhang et al., 2009).

224 As for the physicochemical properties, the statistical analysis of variance (ANOVA) 225 showed significant differences between the different batches of raw strawberries due to 
the different concentrations of the volatile compounds. These differences in the volatile

227 profile are usually a consequence of the natural variability in this fruit (Larsen et al., 1992). Compounds such a hexanal, methyl butyrate, ethyl butyrate, butyl acetate, ethyl hexanoate, 2- hexenyl and 3-hexenyl acetate, vary their concentration depending on the

230 level of ripeness (Azodanlou et al., 2004). Specifically in this work, there were no

231 differences in the butyl acetate concentration between the different raw batches, while

232 huge differences in the 3-hexenyl acetate concentration were observed (table 3).

233 Some authors have pointed out that the concentration of furaneol (2,5-dimetyl-4234 hydroxi-furane), a compound which has an important contribution to the strawberry 235 volatile profile (Sanz, Richardson \& Pérez, 1995; Ulrich, Rapp \& Hoberg, 1995; 236 Schieberle \& Hofmann, 1997; Zabetakis \& Holden, 1997), is very variable depending 237 on the variety and level of ripeness of the strawberries (Pérez, Olías, Sanz \& Olías, 238 1996; Pérez, Olías, Olías \& Sanz, 1999). However, it was not detected in this study, 239 probably because the extraction method did not reach temperatures above $45^{\circ} \mathrm{C}$ which 240 are required to extract some compounds such as furaneol (Escriche, Chiralt, Moreno \& 241 Serra, 2000).

242 Table 3 shows the mean values of the maximum and minimum net variations of the volatile compounds originally detected in the raw strawberries, and detected again in all

24452 strawberry spreads (26 sucrose-isomaltulose spreads and 26 fructose-isomaltulose 245 spreads) after processing. In general terms, the volatile profile was modified with 246 respect to the raw strawberry profile. The concentration of the majority of the volatile 247 compounds was modified, according to the ratio $\left(\left(\mathrm{C}_{0}-\mathrm{C}_{\mathrm{F}}\right) / \mathrm{C}_{\mathrm{F}}\right), \mathrm{C}_{0}$ being the 248 concentration of the volatile compound (VC) in the strawberry spread expressed as $\mu \mathrm{g}$ 249 de VC / $100 \mathrm{~g}$ of raw strawberry, and $\mathrm{C}_{\mathrm{F}}$ the initial concentration of this compound in its 250 correspondent raw batch. Some steps which take place during the processing of 
spreadable products, e.g. cutting or blending, sugar addition, etc., lead to an increase in the activity of enzymes responsible for the development of aroma. This fact has been reported when different kinds of fruit, including strawberries, are submitted to particular stress factors, such as osmotic stress, UV light, a change in $\mathrm{pH}$ or contact with metal ions (Pérez, Sanz, Rios \& Olias, 1993; Zabetakis \& Holden, 1997; Escriche et al., 256 2000).

257 In the present work, some original compounds in fresh strawberries such as ethyl propionate, ethyl hexanoate, 3-hexen-1-yl acetate or 3-hexen-1-ol, were not identified in the strawberry spreads, whereas 13 new compounds were detected after processing.

260 These new compounds were classified as 6 aldehydes, 1 alcohol, 4 furans, 1 terpene, 261 and 1 nitrile as it can be seen in table 4 which shows the concentration of these new compounds expressed as $\mu \mathrm{g}$ de $\mathrm{VC} / 100 \mathrm{~g}$ of spread (net variation cannot be calculated as the initial concentration in the raw batches would be equal to 0 ).

264 It has to be mentioned that of the compounds whose concentration changed after 265 processing, the esters and alcohols decreased their concentration in most of the spreads, except hexyl acetate, ethanol and pentan-2-ol which increased, specifically the last one.

267 The apparition of other compounds such as eucalyptol in the formulated products

268 should be highlighted as well. Some authors have confirmed the liberation of alcohols 269 during the heat treatment of fruit juices as a consequence of the hydrolysis of their 270 corresponding glycoside precursors (Barron \& Etievant, 1990).

271 For the aldehydes, hexenal and 2-hexenal increased their concentration and 6 new 272 aldehydes were also found. This generation of new compounds may be due to the 273 biooxidation of the lipids, mostly non-saturated fatty acids, as a consequence of the cell 274 wall disruption (Yilmaz \& Oxylipin, 2001). 
275 On the other hand, the activation of Maillard reactions, or the catabolism of carotenoids 276 and non-saturated fatty acids promote the generation of volatile compounds related to a 277 cooked flavour (Servili, Selvaggini, Taticchi, Begliomini \& Montedoro, 2000). In this 278 sense, furfural is the most representative aroma generated by Maillard reactions, 279 although it can also originate due to the degradation of ascorbic acid (Barron \& 280 Etievant, 1990). It is important to note that the concentration of furfural in spreadable 281 products was higher in those formulated with fructose-isomaltulose. This could be due 282 to the presence of fructose (a reducing sugar) and the precursors of these reactions, in 283 this formulation. It is well-known that the type of sugar influences both the kind and 284 concentration of the generated flavour compounds during Maillard's Reactions (Fisher $285 \&$ Scott, 1997).

286 A PCA was conducted to evaluate the global effect of processing on the volatile fraction 287 of the spreadable products, from a descriptive point of view. Figure 1 shows the sample scores of the different raw strawberry batches (A-O) and the strawberry spreads (S1 to S26, and F1 to F26), as well as the compound loadings of the PCA analysis performed.

290 The first two components explain $47 \%$ of total variance (PC1 $33 \%$ and PC2 $14 \%$ ). In

291 the score plot, proximity between samples indicates similar behaviour in terms of the volatile profile. In the loading plot, proximity between aromas demonstrates some 293 similarity in their concentration levels.

294 It can be seen that the different raw batches are located on the left, while the formulated 295 products (S1 to S26, and F1 to F26), independent of the sugar mix used (sucrose296 isomaltulose or fructose-isomaltulose), are distributed on the right. Moreover, the raw 297 batches are separated depending on their volatile composition, so those used during the 298 initial months of the experiments (A-E) are placed in the left of this group, while the 299 other raw batches (F-O), with a high level of ripeness, are placed on the right of this 
300 group. This fact confirms that the heterogeneity between the different batches could be

301 due to different levels of ripeness as was mentioned in the characterization of the raw

302 material. On the other hand, the distribution of the strawberry spreads confirms what

303 was mentioned before; some characteristic compounds of raw strawberry, such as ethyl

304 acetate and some alcohols are placed on the left side as they are more related to raw

305 strawberries. On the opposite, compounds generated after processing such as aldehydes

306 and furans are placed on the right side with the strawberry spreads.

307 Once it was clear that the volatile composition of the raw material had an important

308 effect on the volatile profile of the formulated spreads, it was important to evaluate the

309 effect of the different process variables, as well. Thus new PCA analyses were

310 performed, but this time sucrose-isomaltulose spreads were considered separately from

311 fructose-isomaltulose spreads. Moreover, in order to avoid the variation due to the

312 differences between batches, the net mass variations were used to analyze the original

313 volatile compounds in raw strawberries whose concentration was modified as a

314 consequence of processing. Finally, PCAs of generated compounds were also

315 performed.

316 Figure 2 shows the PCA results of the different sucrose-isomaltulose spreads (2a) and

317 fructose-isomaltulose spreads (2b), as well as the volatile compounds whose

318 concentration was modified. While figure 3 shows the PCA results for the volatile

319 compounds generated as a consequence of the processing expressed as $\mu \mathrm{g}$ de $\mathrm{VC} / 100 \mathrm{~g}$

320 of strawberry spread.

321 In these figures, it can be seen that the majority of products are located together,

322 meaning no huge differences in their volatile composition. However, for the modified

323 volatile compounds in sucrose spreadable products, formulations S-19, S-20, S-25 and

324 S-26, are separated from the others, meaning a minor evolution of their volatile profile 
compared with fresh fruit. Moreover, for the volatile compounds generated, in addition

326 to those formulations, formulations S-1, S-2, S-3, S-4, S-21 and S-22 were also

327 separated from the rest. These products happened to be the ones with higher levels of

328 pectin and citric acid, which may suggest a major retention of the original volatile

329 compounds with high levels of these two variables. In fact, some authors have

330 confirmed the hardening of the three-dimensional net formed by pectin-fruit-sugar when

331 the levels of citric acid and pectin are increased (Rauch, 1987; Guichard, 1996; Dervisi,

332 Lamb \& Zabetakis, 2001).

333 On the other hand, the products formulated with fructose, showed different behaviour.

334 In this case, the formulations were grouped closer together than the sucrose spreadable

335 products, which could be due to a major homogeneity between products. Furthermore,

336 only formulations F-1 and F-2 were separated from the rest in the graphs for the

337 modified compounds and the generated compounds. These results would suggest a

338 different behaviour of the food matrix depending on the sugar added, those products

339 formulated with sucrose and higher levels of pectin and citric acid being the ones which

340 showed a better retention of the original volatile compounds and a minor evolution

341 compared to raw strawberry.

\section{4. Conclusions}

344 The volatile profile of spreadable strawberry products was influenced by the ripeness of

345 the raw material as well as by processing conditions. The percentages of pectin and

346 citric acid were the variables which had most influence on the retention of the typical

347 volatile profile of fresh strawberries, especially in the products formulated with sucrose

348 and isomaltulose. Most of the esters and alcohols identified in raw material decreased;

349 whereas new compounds, mostly furans and aldehydes, were generated as a 
consequence of processing. In future studies, it would be interesting to analyze the

351 volatile profile changes as a consequence of storage in order to accurately establish the

352 optimal shelf-life of the final product together with physicochemical and

353 microbiological analysis.

\section{Acknowledgments}

356 Authors would like to thank Dirección General de Investigación del Ministerio de

357 Ciencia y Tecnología (AGL2008-01745/ALI) as well as the Universitat Politècnica de

358 València for the financial support given to this investigation.

\section{References}

361 Ávila, J. M., Beltrán, B., Cuadrado, C., Del Pozo, S., Rodríguez, M. V. \& Ruiz, E. (2009). La Alimentación Española: características nutricionales de los principales alimentos de nuestra dieta. Ministerio de Agricultura, Pesca y Alimentación. Fundación Española de la Nutrición. España. 632 pp.

Azodanlau, R., Darbellay, C., Luisier, J. L., Villettaz, J. C., \& Amado, R. (2003). Quality assessment of strawberries (Fragaria species). Journal of Agricultural and Food Chemistry, 51, 715-721

Azodanlau, R., Darbellay, C., Luisier, J.L., Villettaz, J.C. \& Amado, R. (2004). Changes in flavour and texture during the ripening of strawberries. Eur Food Res Technol, 218:167-172.

Barron, D. \& Etievant, P. X. (1990). The volatile constituents of strawberry jam. $Z$ Lebensm Unters Forsch. 191, 275-289. 
B.O.E. 04/07/07. Real Decreto 863/2003. Norma de calidad para la elaboración, comercialización y venta de confituras, jaleas, mermeladas de frutas y cremas de castañas.

Bood, K. G., \& Zabetakis, I. (2002). The biosynthesis of strawberry flavor (II): Biosynthetic and molecular biology studies. Journal of Food Science, 67: 2-8.

Castelló, M.L., Fito, P.J. \& Chiralt, A. (2006). Effect of osmotic dehydration and vacuum impregnation on respiration rate of cut strawberries. LWT 39, 11711179.

Cavanah, H.M., Hipwell, M. \& Wilkinson J.M. (2003). Antibacterial activity of berry fruits used for culinary purposes. Med Food; 6 (1): 57-61.

Charles F, Willy K, Michael J. 2000. The composition of strawberry aroma is influenced by cultivar, maturity, and storage. HortScience, 35, 1022-1026.

Dervisi, P., Lamb, J. \& Zabetakis, I. (2001) High pressure processing in jam manufacture: effects on textural and colour properties. (2001). Food Chemistry Vol 73, (1), 85-91.

Dhiraj, A., Vattem , R.G. \& Shetty, K. (2005). Enhancing health benefits of berries through phenolic antioxidant enrichment: focus on cranberry. Asia Pac J Clin Nutr. 14 (2):120-130.

Dirinck, P.J., De Pooter, H.L., Willaert, G.A. \& Schamp, N.M. (1981). Flavor quality of cultivated strawberries: the role of the sulfur compounds. J Agric Food Chem 29 (2):316-321.

Escriche, I., Chiralt, A., Moreno, J. \& Serra, J. (2000). Influence of Blanching-osmotic Dehydration Treatments on Volatile Fraction of Strawberries. Journal of Food Science, V 65, (7), 1107-1111. 
Fisher, C. and Scott, T.R. (1997). Chapter 2: Food Flavours. In: Food Flavours. Biology and Chemistry. The Royal Society of Chemistry, Thomas Graham House. Cambridge, England.

Forney, C. F., Kalt, W., McDonald, J. E., \& Jordan, M. A. (1996). Changes in strawberry fruit quality during ripening on and off the plant. Acta Horticulturae,

Forney, C. F. (2001). Horticultural and other factors affecting aroma volatile composition of small fruit. HortTechnology 11,529-538.

Frank, B. H. \& Vasanti S. M. (2010). Sugar-sweetened beverages and risk of obesity and type 2 diabetes: Epidemiologic evidence. Physiology \& Behavior 100, 47-

Fraser, L.K. \& Edwards, K.L. (2010). The association between the geography of fast 409 food outlets and childhood obesity rates in Leeds, UK. Health \& Place 16,

Gillman, M.W., Cupples, L., Gagnon, D., Posner, B., Ellison, R., Castelli, W.P. \& Wolf, P.A. (1995). Protective Effect of fruits and vegetables on development of stroke in Men. J Am Med Assoc; 273: 1113-1117.

Gomes da Silva, M.D.R. \& Chaves das Neves, H.J. (1999). Complementary use of

Gómez, K.C. \& Gómez, A.A. (1984). Statistical procedures for agricultural research. (2nd ed). New York: Jhon Wiley and sons. 
Jeffery, R., Baxter, J., Mcguire, M. \& Linde, J. (2006). Are fast food restaurants an environmental risk factor for obesity?. International Journal of Behavioral Nutrition and Physical Activity 3(2): 2006.

Kaga, T. y Mizutani, T. (1985). "Verwendung von Palatinose fur Nahrungsmittel. Seito Gijutsu Kenkyukaishi” 34, 45-57.

Karabulut, O. A., Lurie, S. \& Droby, S. (2001). Evaluation of the use of sodium bicarbonate, potassium sorbate and yeast antagonist for decreasing posthavest decay of sweet cherries. Postharvest Biology and Technology, 23, 233-236.

Kaur, D., Wani, A., Oberoi, D.P.S. \& Sogi, D.S. (2008). Effect of extraction conditionson lycopene extractions from tomato processing waste sking using response surface methodology. Food Chemestry 108, 711-718.

Kondjoyan, N. \& Berdagué, J. L. (1996). A Compilation of Relative Retention Indices for de Analysis of Aromatic Compounds. Ed. Du laboratoire Flaveur. $1^{\text {st }}$ edition.

Larsen, M., Poll L. \& Olsen, C.E. (1992). Z Lebensm Unters Forsch 195:536-539.

Lina, B.R., Jonker, G. \& Kozianowski, G. (2002). Isomaltulose (Palatinose Re review of biological and toxicologycal studies). Food and Chemical Toxicology, 40, $1375-1381$.

Maarse, H (ed) (1991) Volatile compounds in foods and beverages. Dekker, New York.

Martens, H., \& Naes, T. (1989). Multivariate calibration. Chichester, Wiley. UK.

Matsuyama, J., Sato, T. \& Hoshino, E. (1997). Acid production from palatinose, palatinit, erythritol and maltitol by bacteria isolated from dental plaque on human deciduous teeth. Japanese Journal of Oral Biology, 39, 91-99.

McPhail, D., Chapmanb, G. E. \& Beagan, B. L. (2011). "Too much of that stuff can't be good": Canadian teens, morality, and fast food consumption. Social Science \& Medicine 73, 301-307. 
Peinado, I., Rosa, E., Heredia, A. \& Andrés, A. (2008). Estudio comparativo del color en fresa deshidratada osmóticamente con sacarosa, sorbitol e isomaltulosa. Póster-Artículo, Congreso Iberoamericano sobre Seguridad Alimentaria. V Congreso Español de Ingeniería de Alimentos. Book of Abstracts, p. 165.

Pereira, M., Kartashov, A., Ebbeling, C., Van Horn, L., Slattery, M., Jacobs, D., Ludwig, D. (2005). Fast-food habits, weight gain and insulin resistance (the CARDIA study): 15-year prospective analysis. The lancet, 365:36-42.

Pérez, A. G., Olías, R, Olías, J.M. \& Sanz, C. (1999). Biosyntesis of 4-Hydroxy-2,5455 dimethyl- 3(2H)-furanone and Derivatives in Vitro Grown Strawberries. J. Agric. Food Chem. 47: 655- 658.

Pérez, A.G., Olías, R., Sanz. C. \& Olías, J.M. (1996). Furanones in Strawberries: Evolution during Ripening and Postharvest Shelf Life. J. Agric. Food Chem. 44: $3620-3624$.

Pérez, A. G., Sanz, C., Rios, J. J., y Olias, J. M. (1993). Estudio comparativo de los perfiles aromáticos de manzana, plátano y fresa. Revista Española de Ciencia y Tecnología de Alimentos, 33, 665-677.

Rauch, G.H. (1987). Fabricación de mermeladas. Ed. Acribia, S.A. Zaragoza. España.

Rizzolo, A., Lombardi, P., Lovati, F., Tagliabue, S., \& Testoni, A. (1995). Valutazione della componente aromatica dei frutti di fragola. L'Informatore Agrario, LI(44), 37-41.

467 Rosa, E., Peinado, I., Heredia, A. \& Andrés, A. (2008). Deshidratación osmótica de 468 frutas por vía seca. Una alternativa al uso de disoluciones. Póster-Artículo, Concgreso Iberoamericano sobre Seguridad Alimentaria. V Congreso Español de Ingeniería de Alimentos. Book of Abstracts, p. 168. 
Sanz, C., Richardson, D.G. \& Pérez, A.G. (1995). 2,5-Dimethyl-4- hydroxy-3(2H) furanone and derivatives in strawberries during ripening. ACS, Symp Ser $1995: 268-275$.

Schieberle, P. \& Hofmann, T. (1997). Evaluation of the Character Impact Odorants in Fresh Strawberry Juice by Quantitative Measurements and Sensory Studies on Model Mixtures. J. Agric. Food Chem. 5, 227-232.

Schiweck ,H., Munir, M., Rapp, K. M., Schenider, B. \& Bogel, M. (2000). New developments in the use of sucrose as an industrial bulk chemical. Zuckerindustrie 115, 555-565.

Servili, M., Selvaggini, R., Taticchi, A., Begliomini A.L., \& Montedoro, G.F. (2000). Relationships between the volatile compounds evaluated by solid phase microextraction and the thermal treatment of tomato juice: optimization of the blanching parameters. Food Chemistry, 71, 407-415.

Soria, A. C., Martínez-Castro, I. \& Sanz, I. (2008). Some aspects of dynamic headspace analysis of volatile components in honey. Food Research International, 41, 838848.

Torres, J.D., Chiralt, A. \& Escriche, E. (2012). Development of volatile fraction of fresh cut osmotically treated mango during cold storage. Food Chemistry 130, 921927.

Ulrich, D., Rapp, A. \& Hoberg, E. (1995). Z Lebensm Unters Forsch 200,217-220.

Yilmaz, E., \& Oxylipin (2001). Pathway in the biosynthesis of fresh tomato volatiles. Turk. J. Biol. 25, 351-360.

Zabetakis, I. \& Holden, M.A. (1997). Strawberry Flavour: Analysis and Biosynthesis. J. Sci. Food Agric., 74, 424-434. 
504

505

506

507

508

509

510

511

512

513

514

515

516

517

Zhang, Y.T., Wang, G.X., Dong, J., Zhong, C.F., Kong, J., Li, T.Z., Han, Z.H. (2009). Analysis of Volatile Components in Strawberry Cultivars Xingdu 1 and Xingdu 2 and Their Parents. Agricultural Sciences in China, 8(4), 441-446.

Grab, W. (1998). Fruit Flavours. In: Flavourings: Production, Composition, Applications, Regulations. Ed: Ziegler, E. \& Ziegler, H. Wiley-WCH, Weinheim, Germany.

www.pherobase.com. Date of last view 3.08.2010.

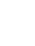

(1)


519 Table 1. Independent variables and their level used for central composite design. composite design.

\begin{tabular}{|c|c|c|c|c|c|c|}
\hline \multirow{2}{*}{$\begin{array}{l}\text { Independent } \\
\text { variables }\end{array}$} & \multirow[t]{2}{*}{ Symbol $^{\mathrm{c}}$} & \multicolumn{5}{|c|}{ Coded variable levels } \\
\hline & & -2 & -1 & $\mathbf{0}$ & 1 & 2 \\
\hline Isomaltulose $(\%)^{\mathrm{a}}$ & $X_{1}$ & 0 & 12.5 & 25 & 37.5 & 50 \\
\hline Pectin $(\%)^{b}$ & $X_{2}$ & 0.5 & 1 & 1.5 & 2 & 2.5 \\
\hline Citric acid $(\%)^{b}$ & $X_{3}$ & 0 & 0.25 & 0.5 & 0.75 & 1 \\
\hline $\begin{array}{l}\text { Heat treatment time } \\
(\text { min) }\end{array}$ & $X_{4}$ & 0 & 5 & 10 & 15 & 20 \\
\hline
\end{tabular}

521

522

523

524

525

a: \% of isomaltulose in the total amount of sugar mix (sucrose-isomaltulose or fructose-isomaltulose).

b: in final product.

c: Symbol with which each independent variable is cited in the text. 
Table 2. Physicochemical values (water activity $\left(\mathrm{a}_{\mathrm{w}}\right)$ moisture content $\left(\mathrm{x}^{\mathrm{w}}\right)$, soluble solids content $\left(\mathrm{x}^{\mathrm{ss}}\right)$, and $\left.\mathrm{pH}\right)$ and F- ratio of the different batches of strawberry. Combination of the different variables performed to obtain 26 products with sucrose and 26 products with fructose. Water activity $\left(\mathrm{a}_{\mathrm{w}}\right)$ and $\mathrm{pH}$ of the spread products $(\mathrm{n}=3)$.

Physicochemical parameters of raw strawberry batches (ANOVA results)

\begin{tabular}{ccccc}
\hline & \multicolumn{2}{c}{ Mean } & F-ratio \\
$\mathbf{a}_{\mathbf{w}}$ & 0.988 & $(0.003)$ & $26.75^{* * *}$ \\
$\mathbf{x}^{\mathbf{w}}$ & 0.925 & $(0.012)$ & 1.04 \\
$\mathbf{x}^{\mathbf{s s}}$ & 0.068 & $(0.006)$ & $148.09 * * *$ \\
$\mathbf{p H}$ & 3.45 & $(0.08)$ & $85.08 * * *$ \\
\hline
\end{tabular}

\begin{tabular}{|c|c|c|c|c|c|c|c|c|c|c|}
\hline \multicolumn{11}{|c|}{ Strawberry spreads } \\
\hline \multirow[b]{2}{*}{$\% \mathrm{~S}$ or $\% \mathrm{~F}$} & \multirow[b]{2}{*}{$\begin{array}{l}X_{I} \\
\%_{\text {I }}\end{array}$} & \multirow{2}{*}{\multicolumn{2}{|c|}{$\begin{array}{ll}X_{2} & X_{3}\end{array}$}} & & \multicolumn{3}{|c|}{ Treatments with Fructose } & \multicolumn{3}{|c|}{ Treatments with Sucrose } \\
\hline & & & & & sample & $\mathbf{a}_{\mathrm{w}}$ & pH & sample & $\mathbf{a}_{\mathrm{w}}$ & pH \\
\hline 62 & 37.5 & 0.75 & 2 & 15 & F-1 & $0.917(0.006)$ & $2.947(0.006)$ & S-1 & $0.913(0.002)$ & $2.980(0.020)$ \\
\hline 62.5 & 37.5 & 0.75 & 2 & 5 & F-2 & $0.915(0.002)$ & $2.930(0.009)$ & S-2 & $0.926(0.003)$ & $2.910(0.030)$ \\
\hline 75 & 25 & 1 & 1.5 & 10 & F-3 & $0.905(0.002)$ & $2.810(0.002)$ & S-3 & $0.917(0.002)$ & $2.820(0.020)$ \\
\hline 62.5 & 37.5 & 0.75 & 1 & 5 & F-4 & $0.905(0.002)$ & $2.897(0.006)$ & S-4 & $0.922(0,002)$ & $2.903(0.006)$ \\
\hline 75 & 25 & 0.5 & 1.5 & 0 & F-5 & $0.911(0.002)$ & $3.003(0.006)$ & S-5 & $0.931(0.002)$ & $3.037(0.006)$ \\
\hline 62.5 & 37.5 & 0.75 & 1 & 15 & F-6 & $0.912(0.002)$ & $2.890(0.020)$ & S-6 & $0.927(0.002)$ & $2.890(0.020)$ \\
\hline 87.5 & 12.5 & 0.75 & 1 & 15 & F-7 & $0.895(0.002)$ & $2.900(0.020)$ & S-7 & $0.906(0.002)$ & $2.910(0.020)$ \\
\hline 100 & 0 & 0.5 & 1.5 & 10 & F-8 & $0.896(0.002)$ & $2.977(0.006)$ & S-8 & $0.922(0.012)$ & $3.020(0.002)$ \\
\hline 75 & 25 & 0.5 & 0.5 & 10 & F-9 & $0.903(0.002)$ & $2.990(0.002)$ & S-9 & $0.934(0.002)$ & $3.017(0.006)$ \\
\hline 87.5 & 12.5 & 0.75 & 1 & 5 & F-10 & $0.912(0.003)$ & $2.797(0.006)$ & S-10 & $0.934(0.003)$ & $2.867(0.006)$ \\
\hline 75 & 25 & 0 & 1.5 & 10 & F-11 & $0.907(0.002)$ & $3.390(0.020)$ & S-11 & $0.929(0.012)$ & $3.440(0.020)$ \\
\hline 75 & 25 & 0.5 & 1.5 & 10 & F-12 & $0.910(0,002)$ & $2.990(0.020)$ & S-12 & $0.916(0.012)$ & $3.023(0.006)$ \\
\hline 87.5 & 12.5 & 0.25 & 1 & 15 & F-13 & $0.900(0.002)$ & $3.180(0.002)$ & S-13 & $0.921(0.002)$ & $3.230(0.020)$ \\
\hline 75 & 25 & 0.5 & 1.5 & 10 & F-14 & $0.905(0.002)$ & $3.010(0.009)$ & S-14 & $0.93(0.002)$ & $3.030(0.020)$ \\
\hline 62.5 & 37.5 & 0.25 & 1 & 5 & F-15 & $0.911(0.002)$ & $3.130(0.002)$ & S-15 & $0.926(0.002)$ & $3.200(0.002)$ \\
\hline 87.5 & 12.5 & 0.25 & 1 & 5 & F-16 & $0.894(0.007)$ & $3.183(0.006)$ & $S-16$ & $0.924(0.002)$ & $3.200(0.020)$ \\
\hline 62.5 & 37,5 & 0.25 & 1 & 15 & F-17 & $0.910(0.002)$ & $3.167(0.006)$ & S-17 & $0.924(0.002)$ & $3.153(0.006)$ \\
\hline 87,5 & 12,5 & 0.25 & 2 & 5 & F-18 & $0.909(0.001)$ & $3.163(0.012)$ & S-18 & $0.919(0.002)$ & $3.160(0.002)$ \\
\hline 75 & 25 & 0.5 & 2.5 & 10 & F-19 & $0.906(0.002)$ & $2.917(0.006)$ & S-19 & $0.922(0.002)$ & $3.007(0.006)$ \\
\hline 87.5 & 12.5 & 0.75 & 2 & 15 & F-20 & $0.902(0.002)$ & $2.873(0.006)$ & S-20 & $0.907(0.002)$ & $2.873(0.006)$ \\
\hline 87.5 & 12.5 & 0.25 & 2 & 15 & F-21 & $0.901(0.002)$ & $3.120(0.002)$ & S-21 & $0.907(0.002)$ & $2.873(0.006)$ \\
\hline 87.5 & 12.5 & 0.75 & 2 & 5 & F-22 & $0.902(0.002)$ & $2.870(0.002)$ & S-22 & $0.921(0.002)$ & $2.897(0.006)$ \\
\hline 75 & 25 & 0.5 & 1.5 & 20 & F-23 & $0.902(0.002)$ & $3.020(0.030)$ & S-23 & $0.916(0.005)$ & $3.040(0.020)$ \\
\hline 62.5 & 37.5 & 0.25 & 2 & 15 & F-24 & $0.905(0.002)$ & $3.190(0.002)$ & S-24 & $0.922(0.002)$ & $3.205(0.002)$ \\
\hline 62.5 & 37.5 & 0.25 & 2 & 5 & F-25 & $0.914(0.002)$ & $3.160(0.009)$ & S-25 & $0.939(0.007)$ & $3.197(0.006)$ \\
\hline 50 & 50 & 0.5 & 1.5 & 10 & F-26 & $0.913(0.002)$ & $3.020(0.002)$ & $S-26$ & $0.903(0.002)$ & $2.980(0.020)$ \\
\hline
\end{tabular}

a: mixture of sugars to reach $50{ }^{\circ}$ Brix in the spreads: $100 \%$ of sugar $=$ sucrose or fructose $\%+$ isomaltulose $\%$. Statistical significance $* * *<0.001$

$\mathrm{S}$ : Sucrose; F: Fructose; I: Isomaltulose.

$X_{1}(\%$ of isomaltulose $), X_{2}(\%$ of pectin $), X_{3}$ (\% of citric acid) and $X_{4}$ (time of thermal treatment (min)). 
Table 3. Retention Index obtained for the volatile compounds identified in the different batches of raw strawberry, concentration of these compounds in raw strawberry expressed as $C_{F}(\mu g / 100 \mathrm{~g}$ raw strawberry) and F-ratio obtained from statistical analysis (ANOVA); Changes of volatile strawberry spreads as a consequence of processing expressed as minimum and maximum concentration ratio $\left(\mathrm{C}_{0}-\mathrm{C}_{\mathrm{F}} / \mathrm{C}_{\mathrm{F}}\right)(\mathrm{n}=3)$

$$
\text { After processing: } \quad \Delta C=\frac{C_{0}-C_{F}}{C_{F}}
$$

Volatile compounds identified in raw strawberry

sucrose-isomaltulose

(S) fructose-isomaltulose

(F)

\begin{tabular}{|c|c|c|c|c|c|c|c|}
\hline & RI & mean & F-ratio & Minimum & Maximum & Minimum & Maximum \\
\hline \multicolumn{8}{|l|}{ Esters } \\
\hline Ethyl acetate & 904 & $129(61)$ & $4.65 * *$ & -0.90 & 2.85 & -0.86 & 1.95 \\
\hline Isopropyl acetate & 911 & $14(5)$ & $7.63 * *$ & -0.63 & 2.76 & -0.60 & 2.00 \\
\hline Methyl propionate & 926 & $7(2)$ & $7.51 * * *$ & -0.85 & 62.48 & -0.90 & 2.39 \\
\hline Ethyl propionate & 972 & $2.4(0.2)$ & $151.06 * * *$ & -0.15 & 0.30 & - & - \\
\hline Methyl butyrate & 1005 & $163(48)$ & $11.8^{* * *}$ & -0.48 & 12.24 & -0.53 & 16.06 \\
\hline Ethyl butyrate & 1054 & $67(12)$ & $27.12 * * *$ & -0.87 & 0.95 & -0.76 & 1.73 \\
\hline Butyl acetate & 1093 & $10(3)$ & $2.11^{\mathrm{ns}}$ & -0.74 & 1.84 & -0.72 & 2.01 \\
\hline Methyl hexanoate & 1205 & $23(6)$ & $3.33^{*}$ & -0.86 & 0.87 & -0.62 & 1.40 \\
\hline Butyl butyrate & 1217 & $5(2)$ & $3.95 *$ & -0.92 & 0.48 & -0.87 & 0.15 \\
\hline Ethyl hexanoate & 1226 & $24(4)$ & $32.69 * *$ & - & - & - & - \\
\hline Hexyl acetate & 1248 & $25(7)$ & $4.48 * *$ & -0.86 & 3.18 & -0.72 & 6.64 \\
\hline 3-Hexen-1-yl, acetate & 1266 & $4.1(0.2)$ & $1716 * * *$ & - & - & - & - \\
\hline 2-Hexen-1-yl, acetate & 1277 & $48(12)$ & $6.03 * *$ & -0.85 & 22.09 & -0.96 & 39.62 \\
\hline Hexyl butyrate & 1432 & $5(2)$ & $5.76^{* *}$ & -0.95 & -0.30 & -0.88 & 0.16 \\
\hline Octyl acetate & 1494 & $8(2)$ & $4.29 *$ & -0.92 & -0.25 & -0.85 & 0.74 \\
\hline Butyl octanoate & 1634 & $6.7(07)$ & $20.59 * * *$ & -0.88 & -0.65 & -0.98 & -0.43 \\
\hline
\end{tabular}

Alcohols

Propan-2-ol

Ethanol

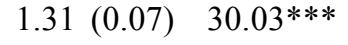

$23(7)$ 


$\begin{array}{lccccccc}\text { 1-Butanol } & 1169 & 3.2(0.4) & 68.62^{* * *} & -0.97 & 60.49 & -0.84 & 71.88 \\ \text { 1-Penten-3-ol } & 1182 & 3.3(0.5) & 4.27^{* *} & -0.77 & 27.35 & -0.70 & 24.65 \\ \text { 3-Methyl-1-butanol } & 1210 & 45(11) & 7.62^{*} & -0.98 & -0.80 & -1.00 & -0.90 \\ \text { 1-Pentanol } & 1236 & 3.3(0.4) & 37.36^{* * *} & -0.91 & 22.12 & -0.70 & 21.54 \\ \text { 1-Hexanol } & 1286 & 67(11) & 23.46^{* * *} & -0.96 & 0.13 & -0.93 & 0.17 \\ \text { 3-Hexen-1-yl } & 1302 & 3(1) & 1.21^{\mathrm{ns}} & - & - & - & - \\ \text { 2-Hexen-1-yl } & 1425 & 14(4) & 3.54^{*} & -0.81 & 3.75 & -0.80 & 5.30 \\ \text { Linalool } & 1564 & 5(1) & 4.39^{* *} & -0.66 & 1.04 & -0.44 & 1.63\end{array}$

\section{Aldehydes}

$\begin{array}{lrrrrrrr}\text { Hexanal } & 1106 & 29(6) & 7.51^{* * *} & -0.55 & 20.05 & -0.400 & 13.33 \\ \text { 2-Hexenal } & 1224 & 39(9) & 2.2^{\mathrm{ns}} & -0.46 & 7.06 & 0.500 & 3.09\end{array}$

\section{Ketones}

$\begin{array}{llllllll}\text { 1-Penten-3-one } & 1042 & 4.3(0.9) & 22.54 * * * & -0.93 & 1.51 & -0.90 & 1.83\end{array}$

Mean (standard deviation).

F-ratio, estimates between groups and within groups ratio (p-value: statistical significance with $95 \%$ of confidence, ns: no significance; $*<0.05 ; * *<0.01 ; * * *<0.001)$.

$\mathrm{C}_{0}$ : concentration of volatile compound (VC) in the strawberry spread expressed as $\mu \mathrm{g}$ de VC / $100 \mathrm{~g}$ of raw strawberry.

$\mathrm{C}_{\mathrm{F}}$ : concentration of volatile compound (VC) in the correspondent batch of raw strawberry expressed as $\mu \mathrm{g}$ de $\mathrm{VC} / 100 \mathrm{~g}$ of raw strawberry. 
Table 4: Retention Index obtained for the new volatile compounds identified after processing; maximum and minimum concentration values of these compounds within the different formulations expressed as $\mu \mathrm{g}$ of $\mathrm{VC} / 100 \mathrm{~g}$ of spread fruit $(\mathrm{n}=3)$.

Volatile compounds after processing ( $\mu \mathrm{g}$ of VC / $100 \mathrm{~g}$ of fruit spread )

\begin{tabular}{|c|c|c|c|c|c|}
\hline & \multicolumn{3}{|c|}{ sucrose-isomaltulose (S) } & \multicolumn{2}{|c|}{ fructose-isomaltulose $(F)$} \\
\hline & RI & Minimum & Maximum & Minimum & Maximum \\
\hline \multicolumn{6}{|l|}{ Aldehydes } \\
\hline 2-Methylbutanal & 930 & 1.62 & 45.00 & 1.11 & 34.85 \\
\hline 3-Methylbutanal & 934 & 0.00 & 8.30 & 1.26 & 12.15 \\
\hline Octanal & 1256 & 0.00 & 1.38 & 0.00 & 0.96 \\
\hline Nonanal & 1418 & 0.35 & 2.07 & 0.35 & 2.04 \\
\hline Decanal & 1524 & 0.34 & 3.57 & 0.30 & 2.72 \\
\hline Benzaldehyde & 1571 & 0.25 & 1.34 & 0.30 & 1.40 \\
\hline \multicolumn{6}{|l|}{ Alcohols } \\
\hline Eucalyptol & 1215 & 0.00 & 5.07 & 0.00 & 4.79 \\
\hline \multicolumn{6}{|l|}{ Furans } \\
\hline Furfural & 1503 & 9.77 & 216.05 & 19.79 & 297.74 \\
\hline 2-Acetilfurane & 1539 & 0.06 & 8.69 & 0.29 & 19.45 \\
\hline 5-Methyl furfural & 1617 & 0.11 & 7.25 & 0.18 & 23.03 \\
\hline Mesifurane & 1632 & 0.00 & 3.97 & 0.38 & 3.69 \\
\hline \multicolumn{6}{|l|}{ Terpens } \\
\hline Limonene & 1208 & 0.18 & 2.57 & 0.26 & 6.42 \\
\hline \multicolumn{6}{|l|}{ Nitriles } \\
\hline Acetonitrile & 1031 & 0.00 & 11.31 & 0.56 & 4.40 \\
\hline
\end{tabular}

